and its associations with disease activity and severity in African Americans with recent-onset rheumatoid arthritis. J Rheumatol 37:275-2812)

[5] Haque UJ, Bartlett SJ (2010) Relationships among vitamin D, disease activity, pain and disability in rheumatoid arthritis. Clin Exp Rheumatol 28:745-747 5 .

Disclosure of Interests: None declared

DOI: 10.1136/annrheumdis-2019-eular.3570

\section{AB1293 SMAD3 GENE POLYMORPHISMS AND EXPRESSION IN SERUM AND CARTILAGE INFLUENCE THE RISK OF KNEE OSTEOARTHRITIS}

Rajeswar Nath Srivastava, Amar Chandra Sharma, Sudeepti Srivastava, Saloni Raj. King George's Medical University, orthopaedic sugery, Lucknow, India

Background: Knee Osteoarthritis (KOA) is the most common degenerative arthritis, a type of arthritis that is caused by breakdown of articular cartilage with eventual loss of the cartilage of the joints. Smad3 is a key intracellular messenger in the transforming growth factor $\beta$ signaling pathway. Previous study suggested Smad3 gene mutation is a possible predisposing factor for human $\mathrm{OA}$ and found gene mutation in $\mathrm{OA}$, providing insight into the function of SMAD3 mediated TGF-b signals in the development of $\mathrm{OA}$ and also suggested that Smad3 gene mutation may be a risk factor for genetic susceptibilities to OA. In this case control study, we investigated the possible correlation between the SNPs Smal (C/T; rs6494629), Fokl (A/C; rs2289263) in Smad3 gene and susceptibility to knee $\mathrm{OA}$ and validated in serum and cartilage.

Objectives: To investigate the possible association between SNPS (rs6494629 and rs2289263) of the Smad3 gene and KOA.

Methods: In this study cases consisted of men and women $\geq 40$ years that fulfilled American College of Rheumatology (ACR) clinical and radiographic criteria for knee OA. Venous blood samples were obtained from all cases as well as controls for genetic analysis. Polymerase chain reactions were performed for SNP analysis using specific primer. Total protein was measured in serum by an enzyme linked immunosorbent assay according to the manufacturer's Protocol (ELISA) and in cartilage tissue done by western blot.

Results: A total of 200 cases that confirmed radiographic knee OA and equal number of age and sex matched healthy controls were enrolled. There was no significant difference in demographic characteristics between the cases and controls. A SNP (rs6494629 and rs2289263) mapping to intron 1 of SMAD3 was associated with knee OA ( $P<$ 0.013 and $P<0.044$, respectively). Within the SNPs (rs6494629) of Smad3 gene, genotype CC and CT was found to be significantly $(p<0.013)$ associated with knee OA as compared with the CC genotype and SNP rs2289263,genotype CC and CA was found to be significantly $(p<0.044)$ associated with knee $O A$ as compared with the AA genotype. In addition when alleles were compared, $\mathrm{C}$ allele of both the studied SNP was observed to be significantly associated with knee OA. Serum levels of Smad3 in KOA patients with rs6494629 TT, CT and $\mathrm{CC}$ genotypes were significantly higher than healthy subjects with the same rs6494629C/T genotypes (all $\mathrm{P}<0.0001, \mathrm{P}<0.0006, \mathrm{P}<$ 0.017 respectively). Increased serum levels of Smad3 were also observed in KOA patients with rs2289263 AA, CA and CC genotypes compared to controls (all $\mathrm{P}<0.006, \mathrm{P}<0.0006, \mathrm{P}<0.004$ ). We performed Immunoblot analysis on cartilage tissue from 15 cases and 10 controls. The smad3 level in cases was significantly higher than controls $(\mathrm{P}<0.006)$

Conclusion: Our data indicate that genetic variation in the SMAD3 gene is involved in the risk of knee OA in North Indian populations, confirming the results from previous studies on the potential importance of this gene in the pathogenesis of OA. Further we also validated these genetic variations at protein level in both blood and tissue and found significant association.

\section{REFERENCES}

[1] Valdes AM, Spector TD, Tamm A, Kisand K, Doherty SA, Dennison EM. Genetic variation in the SMAD3 gene is associated with hip and knee osteoarthritis. Arthritis and rheumatism. 2010;10.1002/art.27530

[2] Su SL, Yang HY, Lee HS, Huang GS, Lee CH, Liu WS. Gene-gene interactions between TGF-b/Smad3 signalling pathway polymorphisms affect susceptibility to knee osteoarthritis. BMJ Open. 2015;5:e007931.

Disclosure of Interests: None declared

DOI: 10.1136/annrheumdis-2019-eular.6897

\section{AB1294 \\ IMPACT OF INFERTILITY, PREGNANCY LOSS AND CHILDBEARING DECISION ON FAMILY SIZE IN WOMEN WITH SYSTEMIC LUPUS ERYTHEMATOSUS AND RHEUMATOID ARTHRITIS}

Dayang Masyrinartie Suahilai ${ }^{1}$, Nurulraziquin Mohd Jamid ${ }^{1}$, Noraini Mat Husin ${ }^{2}$, Hairul Hadi Ariff', Rashidah Bahari ${ }^{3}$, Nor Shuhaila Shahril ${ }^{1}{ }^{1}$ Hospital Putrajaya, Medicine, Putrajaya, Malaysia; ${ }^{2}$ Hospital Raja Permaisuri Bainun, Ipoh, Medicine, Ipoh, Malaysia; ${ }^{3}$ Hospital Putrajaya, Clinical Research Centre, Putrajaya, Malaysia

Background: Systemic lupus erythematosus (SLE) and Rheumatoid Arthritis (RA) often affects women in their reproductive years. These women are faced with a life-long illness that may have considerable impact not only on their physical health, but also on their reproductive potential. Fertility of these women may also be affected by the disease, treatment and/or organ damage.

Objectives: To determine the role of infertility, pregnancy loss and childbearing decision and patients concerns on family size in women with SLE and RA

Methods: A cross sectional study using a self-administered reproductive history questionnaire completed by woman with SLE/RA attending Rheumatology clinic follow up in Hospital Putrajaya, Hospital Tengku Ampuan Rahimah, and Hospital Raja Permaisuri Bainun, Malaysia from 1 January 2017 to 30 June 2017.

Within each disease cohort, women were identified into 3 groups, those with fewer children than planned (group A), those with same number of planned children (group B) and those with completed family or not interested in having any children (group C). Data on number of children, pregnancies, misscariges and self reported infertility were recorded.For group $\mathrm{A}$, data on patient concerns and the factors that could impact family building were also obtained.

Results: Total of 110 women with SLE and 91 women with RA were surveyed. The mean age of women with SLE and RA were 37.6 years (+/- SD 7.4) and 45.37 years (+/- SD 11.7) respectively. Majority of women $(48.8 \%)$ with SLE and RA were in group A with $59 \%(n=65)$ of women with SLE and $33 \%(n=33)$ of women with RA had fewer children than originally planned.

The average numbers of pregnancies were similar in both cohorts, but women with SLE had 1 less child and were more likely to report infertility and had higher rate of miscarriages (Table 1). SLE group A had a similar number of pregnancies, but 1 less child compared to SLE group $B$ and C (Table 2). Similarly, among women with RA, group A had 1 less child with similar number pregnancies and miscarriage rate (Table 2). In both groups of women, concerns about inability to care for a child, damage from medications, and genetic transmission of their disease were associated with a lower pregnancy rate.

Table 1. Number of pregnancies, live births, miscarriages and rate of infertility among women with SLE and RA*

\begin{tabular}{lccc}
\hline \hline & SLE & RA & P \\
No. of pregnancies & 2.28 & 2.60 & 0.128 \\
& \pm 1.626 & \pm 1.949 & \\
No. of children & 1.85 & 2.19 & $\mathbf{0 . 0 1 9}$ \\
& \pm 1.235 & \pm 1.731 & \\
No. of miscarriages & 0.46 & 0.36 & $\mathbf{0 . 0 4 0}$ \\
& \pm 0.809 & \pm 0.659 & \\
No reporting infertility & $5(4.5)$ & $2(2.2)$ & 0.366 \\
$(\%)$ & & & \\
\hline
\end{tabular}

*values are the mean + /- SD unless otherwise indicated

Table 2. Pregnancy outcomes for women with SLE $(n=110)$ and RA $(n=91)$ *

\begin{tabular}{|c|c|c|c|c|c|c|}
\hline \multirow[b]{3}{*}{$\begin{array}{l}\text { No. of woman, } n \\
\text { (\%) }\end{array}$} & \multicolumn{2}{|c|}{$\begin{array}{l}\text { Fewer children than } \\
\text { desired } \\
\text { (group A) }\end{array}$} & \multicolumn{2}{|c|}{$\begin{array}{l}\text { Expected number of } \\
\text { children } \\
\text { (group B) }\end{array}$} & \multicolumn{2}{|c|}{$\begin{array}{l}\text { completed family } \\
\text { (group C) }\end{array}$} \\
\hline & SLE & RA & SLE & RA & SLE & RA \\
\hline & $65(59.1)$ & 33 (36.3) & $20(18.2)$ & $31(34.1)$ & $25(22.7)$ & 27 (29.7) \\
\hline $\begin{array}{l}\text { No. of } \\
\text { pregnancies }\end{array}$ & $\begin{array}{c}2.11 \pm \\
1.592\end{array}$ & $\begin{array}{c}2.03 \pm \\
1.723\end{array}$ & $\begin{array}{l}2.3 \pm \\
0.865\end{array}$ & $\begin{array}{c}2.81 \pm \\
2.12\end{array}$ & $\begin{array}{l}2.72 \pm \\
2.092\end{array}$ & $\begin{array}{c}3.07 \pm \\
1.9\end{array}$ \\
\hline No. of children & $\begin{array}{l}1.57 \pm \\
1.212\end{array}$ & $\begin{array}{l}1.55 \pm \\
1.416\end{array}$ & $\begin{array}{l}2.1 \pm \\
0.553\end{array}$ & $\begin{array}{c}2.39 \pm \\
4.856\end{array}$ & $\begin{array}{c}2.36 \pm \\
1.497\end{array}$ & $\begin{array}{c}2.74 \pm \\
1.745\end{array}$ \\
\hline $\begin{array}{l}\text { No. of } \\
\text { miscarriages }\end{array}$ & $\begin{array}{c}0.51 \pm \\
0.831\end{array}$ & $\begin{array}{l}0.36 \pm \\
0.603\end{array}$ & $\begin{array}{c}0.25 \pm \\
0.716\end{array}$ & $\begin{array}{l}0.32 \pm \\
0.653\end{array}$ & $\begin{array}{c}0.52 \pm \\
0.823\end{array}$ & $\begin{array}{l}0.41 \pm \\
0.747\end{array}$ \\
\hline
\end{tabular}

*values are the mean $+/-$ SD unless otherwise indicated

Conclusion: In this population, more than half of women with RA or SLE had fewer children than desired. Other than patient choice, infertility and miscarriage also play an important role on family size. 


\section{REFERENCES}

[1] Clowse, et al. Effects of Infertility, Pregnancy Loss, and Patient Concerns on Family Size of Women With Rheumatoid Arthritis and Systemic Lupus Erythematosus. Arthritis Care \& Research.2012; 64 (5):668-674

[2] Vinet at al. Systemic Lupus Erythematosus in Women: Impact on Family Size. Arthritis \& Rheumatism (Arthritis Care \& Research).2008; 59 (11);1656-1660

Disclosure of Interests: None declared

DOI: 10.1136/annrheumdis-2019-eular.4441

\section{AB1295 DISCREPANCIES BETWEEN THE RHEUMATOID ARTHRITIS PATIENT POPULATION IN RANDOMIZED CONTROLLED TRIALS OF BIOLOGICS AND THAT IN REAL-WORLD SETTINGS: A STUDY USING THE IORRA COHORT}

Eri Sugano ${ }^{1}$, Eiichi Tanaka ${ }^{1}$, Eisuke Inoue ${ }^{1}$, Mai Abe ${ }^{1}$, Mika Kawano ${ }^{1}$, Kumiko Saka ${ }^{1}$, Naohiro Sugitani ${ }^{2}$, Yoko Shimizu ${ }^{1}$, Moeko Ochiai ${ }^{1}$, Rei Yamaguchi ${ }^{1}$, Naoki Sugimoto ${ }^{1}$, Katsunori lkari ${ }^{1}$, Ayako Nakajima ${ }^{2}$ Atsuo Taniguchi ${ }^{1}$, Hisashi Yamanaka ${ }^{1}{ }^{~}$ Institute of Rheumatology Tokyo Women's Medical University, tokyo, Japan; ${ }^{2}$ Mie University Hospital, Center for Rheumatic Diseases, Mie, Japan

Background: Randomized controlled trials (RCTs), which are currently considered to provide the highest level of evidence, include patients with high disease activity and exclude those with comorbidities often seen in real-world settings. With the increasing recognition of the importance of real-world evidence, attention is being paid to discrepancies between RCT-based evidence and the patient population in routine clinical practice; however, few reports assessing these gaps in the context of rheumatoid arthritis (RA) are available.

Objectives: To evaluate the proportion of patients meeting the inclusion criteria in RCTs of biologics for the treatment of RA conducted in Japan using the real-world IORRA cohort.

Methods: The inclusion criteria used in Phase 2 or Phase 3 RCTs of the following biological DMARDs (bDMARDs) were extracted: infliximab (IFX), etanercept (ETN), adalimumab (ADA), golimumab (GLM), certolizumab (CZP), abatacept (ABT), tocilizumab (TCZ), and infliximab BS (IFXBS). Patients participating in the IORRA study during the period when each RCT was conducted (Cohort A) and those who initiated treatment with each bDMARD at our institute in 2016 (Cohort B) were included in the analysis. The proportion of RA patients in Cohorts A and B who met the RCT inclusion criteria was assessed.

Results: A total of 19 RCTs were conducted in Japan (IFX, 2; ETN, 1; ADA, 2; GLM, 2; CZP, 3; ABT, 2; TCZ, 6; IFX-BS, 1). Key trial inclusion criteria were age, RA duration, tender joint count (TJC), swollen joint count (SJC), erythrocyte sedimentation rate (ESR), C-reactive protein (CRP), methotrexate (MTX) use, corticosteroid use, and prior bDMARD therapy. The number of patients participating in the IORRA analysis during the period when each RCT was conducted ranged from 1,777 to 6,843 (mean: 5,470) (Cohort A). The median/average [range] proportion of RA patients meeting all RCT inclusion criteria was $0.6 \% / 2.3 \%$ [range: $0.0 \%-16.2 \%]$. The proportion by criterion was $93.9 \% / 92.4 \%[59.7 \%-99.9 \%]$ for age, $68.9 \% / 57.1 \%[9.0 \%-99.6 \%]$ for RA duration, $11.6 \% / 16.0 \%[4.5 \%$ $33.0 \%]$ for SJC, $14.6 \% / 17.2 \%$ [3.7\%-33.9\%] for TJC, $27.8 \% / 32.1 \%$ [20.1\%-49.8\%] for CRP, 60.2\%/58.7\% [43.7\%-66.8\%] for ESR, $14.8 \% /$ 40.6\% [13.1\%-73.9\%] for MTX use, 99.5\%/99.3\% [98.5\%-99.8] for prednisolone (PSL) use, and 91.9\%/92.0\% [85.6\%-98.0\%] for prior bDMARD use. In Cohort A, the proportion of RA patients meeting the RCT inclusion criteria was low, particularly with respect to SJC, TJC, and MTX use. Among 337 patients who initiated bDMARD therapy at our institute in 2016, a total of 139 biologic-naïve patients (IFX, 3; ETN, 33; ADA, 11; GLM, 21; CZP, 17; ABT, 25; TCZ, 28; IFX-BS, 1) were included in the analysis (Cohort B). In Cohort B, the median/average [range] proportion of RA patients meeting all RCT inclusion criteria was $0 \% / 8.2 \%$ [0.0\%-54.2\%]. The proportion by criterion was 100\%/99.1\% [94.1\%-100\%] for age, $20.8 \% / 26.5 \%[0.0 \%-57.1 \%]$ for SJC, $11.8 \% / 17.0 \%[0.0 \%-50.0 \%]$ for TJC, 33.3\%/34.9\% [0.0\%-66.7\%] for CRP, $58.3 \% / 57.3 \%[0.0 \%-75.0 \%]$ for ESR, 23.5\%/35.5\% [0.0\%-100\%] for MTX use, and $100 \% / 100 \%$ [100\%] for PSL use. As in Cohort A, the proportion of RA patients meeting the inclusion criteria was low in Cohort B, particularly with respect to SJC, TJC, and MTX use.

Conclusion: It is important to note that evidence from RCTs of bDMARDs is based on a limited RA population in real-world settings.

Disclosure of Interests: Eri Sugano: None declared, Eiichi Tanaka Speakers bureau: Abbvie, Asahi Kasei pharma co., Bristol Myers Squibb,
Chugai Pharmaceutical, Daiichi Sankyo Co., Eisai Pharmaceutical, Janssen Pharmaceutical K.K., Nippon Kayaku, Pfizer, Takeda Pharmaceutical, Taisho Toyama Pharmaceutical Co., and UCB Pharma., Eisuke Inoue: None declared, Mai Abe: None declared, Mika Kawano: None declared, Kumiko Saka: None declared, Naohiro Sugitani: None declared, Yoko Shimizu: None declared, Moeko Ochiai: None declared, Rei Yamaguchi: None declared, Naoki Sugimoto: None declared, Katsunori Ikari: None declared, Ayako Nakajima Grant/research support from: Asahi Kasei pharma co., Chugai Pharmaceutical, Daiichi Sankyo Co., Pfizer, Kissei Pharmaceutical Co., and Mitsubishi Tanabe Pharma Corporation., Atsuo Taniguchi: None declared, Hisashi Yamanaka Grant/research support from: AbbVie, Eisai, Bristol-Meyers, Novartis, Behringer, Astellas, Kaken, Nippon-Shinyaku, Pfizer, UCB, Ayumi, Ono, Daiichi-Sankyo, Taisyo-Toyama, Takeda, Tanabe-Mitsubishi, Chugai, Teijin Pharma, Torii, YLbio, Speakers bureau: Bristol-Meyers, Astellas, Pfizer, Daiichi-Sankyo, Takeda, TanabeMitsubishi, Chugai, Teijin Pharma, YLbio DOI: 10.1136/annrheumdis-2019-eular.6570

\section{AB1296 PREGNANCY IN WOMEN WITH SYSTEMIC LUPUS ERYTHEMATOSUS: MATERNAL AND FETAL COMPLICATIONS}

Tatiana Kirsanova ${ }^{1}$, Olga Tsatsulina ${ }^{2}$, Maria Vinogradova ${ }^{1}$, Tatiana Fedorova $^{1}$, Nina Rozina ${ }^{2}$, Elizaveta Rumyantseva ${ }^{2} .{ }^{1}$ Federal State Budget Institution "Research Center for Obstetrics, Gynecology and Perinatology", Moscow, Russian Federation; ${ }^{2}$ Moscow State University, Fundamental Medicine, Moskva, Russian Federation

Background: Systemic lupus erythematosus is a chronic autoimmune disease often affecting women in fertile age. The physiological changes in T-helpers (Th1/Th2) activity balance during pregnancy can cause SLE flare. Women with SLE are at high risk for maternal and fetal complications. The high SLE activity is associated with higher risk of PE and lower birth weight, compared with population controls. Nevertheless, no detailed analysis of the relationship between clinical features/laboratory parameters and unfavorable pregnancy outcome in patients with SLE has been carried out in the recent studies.

Objectives: This study aimed to analyze influence of SLE activity, laboratory parameters and medications on risk of maternal and fetal complications.

Methods: A retrospective single-center cohort study 11/2014-12/2018: 43 pregnancies in 42 patients with proved SLE and $>20$ weeks of gestation, mean age was 31,5 years. Renal function at conception and after delivery, pregnancy outcomes, clinical and laboratory parameters were collected. PE was diagnosed by the 2008 WHO criteria. The sFIT/PIGF ratio was used as the main differential marker to exclude lupus nephritis exacerbation in cases of increased proteinuria.

Age of the patients, SLE activity, hemoglobin and platelet levels, glomerular filtration rate, serum creatinine, AST, ALT, fibrinogen, D-dimer, aPTT, antinuclear factor and antiphospholipid antibodies concentrations, the using/non-use of glucocorticoids, hydroxychloroquine, low molecular weight heparins and aspirin were analyzed as potential risk factors of unfavorable pregnancy outcomes: PE, premature delivery, low birth weight, low Apgar score at 1 and 5 minutes after birth.

Results: In 12 cases $(27.9 \%)$ there was no activity of SLE, in 16 cases $(37.2 \%)$ there was low activity, in five $(11.6 \%)$ - moderate, in three $(7 \%)$ - high, in seven cases (16.3\%) SLE activity was not assessed. SLE activity showed significant negative correlation with week at which labor occurred $(p=0.003, R=-0.477)$ and birth weight $(p=0.005, R=-$ 0.461 ) and we found a significant fivefold increase in preeclampsia in patients with high activity of SLE $(p=0.011, \mathrm{OR}=4.95,95 \% \mathrm{Cl} 1.449$ to 16.931). Hemoglobin levels in third trimester correlated positively with birth weight $(p=0.04, R=0.322)$. The dosage of glucocorticoids showed a significant correlation with week of delivery $(p=0.011, R=$ 0.382). Interestingly, the increase of aPTT in. the third trimester had an almost significant effect on the risk of developing PE $(p=0.059, O R=$ $1.237,95 \% \mathrm{Cl}$ 0.958-1.596). Unfortunately, lupus anticoagulant (LA) at that moment was not measured. Other studied parameters were not associated with risk of $\mathrm{PE}$.

Conclusion: High SLE activity significantly increases the risk of gestational complications and unfavorable pregnancy outcomes. We suggest that regular monitoring of antiphospholipid antibodies, especially LA, is needed. In this study, laboratory parameters did not significantly affect the risk of PE. 